\title{
Policing a Negotiated World: A Partial Test of Klinger's Ecological Theory of Policing
}

\author{
Travis A. Taniguchi ${ }^{1}$ Christopher Salvatore ${ }^{2}$
}

Published online: 20 January 2017

(C) The Author(s) 2017. This article is published with open access at Springerlink.com

\begin{abstract}
Objectives Klinger's (Criminology 35(2): 277-306, 1997) ecological theory of policing addresses the intersection of environment and police organizational structure on police patrol practices. The current study addresses the following question: 'Is police response to calls for service influenced by the level of serious violent crime or the level of officer staffing?'

Methods This question was addressed using crime, incident, and staffing data supplied by the Philadelphia Police Department. The dependent variable was the number of unfounded events per month, per police district, from 2004 to 2008. Analysis controlled for linear and non-linear trends, average monthly temperature, month length, and spatial effects. Data were analyzed using repeated measures multilevel modeling.

Results Findings suggested that the quantity of unfounded events was associated with both workload and officer staffing levels. Consistent with theoretical predictions, higher workload was associated with more unfounded incidents while higher levels of officer staffing was associated with fewer unfounded incidents, net of ongoing trends and spatial effects.

Conclusions These findings are consistent with the Ecological Theory of Policing and suggest that officers may shed workload in response to higher demands for service or lower levels of officer availability.
\end{abstract}

Keywords Policing · Negotiated order · Ecological theory of policing

Travis A. Taniguchi

taniguchi@rti.org

Christopher Salvatore

salvatorec@montclair.edu

1 Research Criminologist, RTI International, 3040 E. Cornwallis Rd., Research Triangle Park, NC 27706, USA

2 Department of Justice Studies, Montclair State University, 1 Normal Ave., Montclair, NJ 07043, USA 


\section{Introduction}

Scholars have argued that neighborhood effects on police behaviors are influenced by a multitude of organization and community characteristics (Sobal 2010a). Klinger's ecological theory ${ }^{1}$ describes policing as a balance between numerous forces: formal and informal cultures, legal regulations and work group norms, resources and enforcement, and individual and collective rights. These characteristics have been discussed, and continue to be examined, by many scholars (e.g., Phillips and Sobal 2011, 2012; Sobal 2010a, b; Smith 1986; Slovak 1987; Sun 2002; Terrill and Reisig 2003). Klinger's theory argues that officer actions can be characterized along a continuum of formal authority ranging from vigorous to lenient, where arrest represents more vigor than nonarrest, filing a report more vigor than not filing a report, and so forth. The theory predicts that the vigor through which officers use their formal authority varies inversely to the district crime level because officers (1) view crime as more acceptable in higher-crime areas; (2) view victims less sympathetically; (3) continually deal with repeat offenders in high-crime areas, leading to officer cynicism; and (4) have less time to allocated to resolving service calls in higher-crime districts (Klinger 1997).

Police operate with a great deal of autonomy, both at an organizational level (Brogden 1982; Marenin 1985) and as individual officers (Bittner 1967; De Lint 2000; Ericson 1982; Lundman 1979). Klinger argued that, nevertheless, officers do not act without constraints. These constraints either come from formal bureaucratic regulation or develop as part of the norms within a work group; it is these informal work group constraints that Klinger's ecological theory focuses on. Saying that officers operate with autonomy does not necessarily imply that officers will exercise their discretion in the same way in all locations. Stated differently, officers may alter their discretionary behavior on the basis of factors related to the individual incident, or of the environmental characteristics of where the crime occurred. This suggests that there may be spatial variations in how and where officers exercise discretion.

Klinger's theory focused on explaining why police behavior varies and what role police organizations and ecological factors have in influencing police behaviors. The theory has been incorporated into numerous areas of policing, but it has had relatively few empirical tests given its prevalence. The minimal testing that Klinger's theory has received may be due to the difficulty of measuring key constructs, as well as to the challenges of using the level of aggregation necessary to explore the role of broad ecological influences on police activities.

The primary goal of the current study is to examine a portion of Klinger's theory. Specifically, we test the influence of organizational and environmental contextual factors, guided by Klinger's theory, on one measure of officer vigor. To date, few studies have taken this approach to examining Klinger's theory. The study builds on prior research that has tested aspects of Klinger's theory and adds new analytic strategies that prior studies have not used. The results of this study have implications for both theory and practice, and they add to the growing literature examining the influence of ecological and organization factors on police behavior.

\footnotetext{
1 In the interest of clarity in this article, the term "ecological theory" is used in reference to Klinger's (1997) ecological theory of policing. However, Klinger's is not the only theory that attempts to explain the spatial variation found in police activity.
} 


\section{Relevant Literature}

\section{The Ecology of Police Patrol}

Research has demonstrated that police officers have broad understandings of the geographic areas to which they are assigned. These understandings often shape, and are shaped by, interactions between the officer and the community. Numerous researchers have noted the importance of how police conceptualize the space in which they work (Brown 1981; Herbert 1997). Knowledge of dangerous places, situations, or people is shared among officers so that common themes develop among patrol work groups. Klinger (1997) proposes a mediated model that links two factors driving the development of work group norms regarding the vigor used to enforce laws: the workload of the district and the prevalence of other social (noncriminal) problems in a district. The district workload sharply affects the amount of vigor officers are willing to expend on less-serious offenses. Officers in districts with higher workloads will expend less vigor toward less-serious events than officers in districts with lower workloads. Districts that are high in crime are also likely to be high in other noncriminal social problems such as mental illness, homelessness, and alcoholism (Faris 1948).

Although it is not the focus of the present study, it is important to note that scholars have found that certain neighborhoods may be criminogenic despite factors such as turnover in racial/ethnic groups (Stark 1987). As such, police may also have a distinct attitude toward a specific neighborhood on the basis of its reputation. In Klinger's model, workload and the prevalence of these other social problems drives the development of work group norms. These work group norms develop at the district level of the organizational structure. The variation in workload, community demographics, and environmental factors are the focus of the current study.

Klinger identified several organizational factors that drive the development of stable work groups centered on police patrol. Klinger asserts that these factors, which are consistent across jurisdictions, have to do with how police patrols are organized and how the command structure deals with the activities of the patrol officer. First, police patrol is usually a clearly identifiable group, separate from other branches of the organization. Second, officers generally patrol a district on a semi-permanent basis. Finally, two or more officers usually respond to any incident that may pose a risk to officer safety. This means that officers must work in groups to resolve many situations. The stability of patrol officer work groups and group interaction is important because it builds a district wide shared understanding of the community in which they police.

Turning to work rules, Klinger argues that regardless of the type, structure, or nature of the organizational structure, administrators can provide only limited supervision of patrol officers. Formal rules cannot cope with the complexity of interactions that police are required to handle. Administrators must defer to broad formal mandates regarding the appropriate actions in any particular situation. This leaves patrol officers with a high degree of autonomy regarding the enforcement (or non-enforcement) of laws. Administrators in law enforcement organizations are further hampered by the spatial and temporal distribution of police patrol work. As supervisors get more distant, either organizationally, spatially, or temporally, they have less direct influence over how patrol officers handle any particular situation.

This separation from supervisors does not, however, indicate that individual officers are able to exercise their discretion in isolation from other members of the organization. 
Although some authors argue that each officer constructs individual styles of policing (Brown 1981; White 1972), Klinger instead argues that a combination of individual and organizational factors determines how patrol work is conducted. Instead, groups of officers conduct negotiations to effectively set rules that allow them to handle situations within the organizational framework.

Klinger's ecological theory of policing suggests that rule negotiations occur at the district level. These negotiations are based, at least in part, on the understanding of districtlevel deviance shared among officer work groups. First, districts vary on both the quantity and type of work that an officer may encounter. Officers in high-crime districts tend to be busier than officers in low-crime districts, even after accounting for variations in officer staffing. Second, officers within a district share a common communications system. This shared communication system informs officers how busy their peers are and what types of activities other officers are conducting. Third, how officers perceive district-level deviance is shaped by the public life of residents and visitors in their patrol areas. In high-crime districts, officers are more likely to see criminals in public and are more likely to see crimes committed in public (Klinger 1997). High-crime areas also have a greater proportion of highly visible activities such as prostitution and open-air drug distribution (Rengert et al. 2005; Weisburd et al. 2006).

Klinger's negotiated order theory is grounded in two theoretical perspectives: stability of punishment and the overload hypothesis. The stability of punishment theory argues that there is a general equilibration in the levels of deviance in a given population over time. In high-crime areas, only highly deviant acts are punished (Durkheim 1938). Acts that would be considered deviant in low-crime areas are seen acceptable in high-crime areas (Moynihan 1993). The overload hypothesis explains the relationship between deviance and quantity of punishment through limitations in the capacity of social control institutions (Geerken and Gove 1975; Geerken and Gove 1977). Increased crime rates strain the capacity of social control institutions, resulting in less energy being devoted to each case, and thereby reducing the certainty of punishment. Both theories predict an inverse relationship between punishment and crime rates: as crime levels increase, the amount of punishment meted out cannot keep pace. Compensation for changing levels of deviance can come from any number of locations throughout the criminal justice system. Klinger (1997) suggests that police patrol officers function as early screeners within this system and that the intensity with which they pursue law enforcement is at least partially contingent upon the prevailing level of crime in an area.

To summarize, Klinger's ecological theory argues that officer understanding of district deviance is shaped by the district workload, a shared understanding of district deviance, and officers' observing deviance occurring in public spaces. These understandings are shared among officers within a district because these factors are stable over time and because patrol work tends to be group work. These understandings ultimately form the basis of work group norms.

\section{Negotiated Order in Police Work}

The early theoretical framework of negotiated order developed from a study of work groups in two psychiatric hospitals (Strauss et al. 1963). These researchers were concerned with how order could be maintained within the complex organizational framework of the hospital. Traditional rational-bureaucratic theory (Weber 1947) suggested that actors should turn to administratively defined rules and regulations when dealing with complex interactions (Udy 1959). Strauss et al. (1963) identified two limitations with this 
perspective. First, many actors within the system were not fully aware of all the rules. Second, hospital rules and regulations were neither extensive nor explicit enough to deal with the many situations that personnel encountered. This observation suggested that an organization may have too many rules and, at the same time, these rules may lack the depth necessary to encompass all potential situations an employee can encounter.

The ecological theory of policing uses negotiated order perspective to explain how differences across patrol districts lead to differences in negotiated work group rules. Negotiated rules are determined by environments, mandates, and the work that must be done. The environment is of particular importance because patrol officers become totally immersed in the social and ecological context of their districts (Reiss and Bordura 1967). Klinger (1997) articulates these ideas through four points: normal crime, deservedness of victims, police cynicism, and workload.

First, officers in high-crime districts tend to define deviance downward. These officers bear witness to serious crimes more frequently than officers in lower-crime districts. Officers in high-crime districts, therefore, view disorder-related offenses as normal and not warranting a vigorous police response. As district-level deviance increases, officers will be more likely than their peers in low-crime districts to view more highly serious crime as more normal or acceptable.

Second, officers in both high-crime and low-crime districts believe that many victims bring crime upon themselves and that many victims of crime are themselves criminals. The criminal in one situation can quickly become the victim in another (Lauritsen et al. 1991). Officers believe that when offenders are victimized, they are less worthy of a vigorous police response. As district-level deviance increases, officers will believe that fewer victims of crime are worthy of vigorous police response.

Third, officers in high-crime districts are more cynical than officers in low-crime districts. High-crime areas can be perceived as an indication of a failed criminal justice system. Officers in high-crime districts arrest the same people time and again. These repeated contacts with the same criminals leave officers with the feeling that, regardless of their actions, criminals will be returned to the street and crime will remain high in that district. Officers in high-crime districts deal with this cyclical process to a greater degree than officers in low-crime districts. This increases cynicism and reduces officer vigor.

Finally, districts with a greater workload will be less vigorous in enforcing laws. Officers are aware of the workload in their assigned district; they know that a backlog of calls requiring their attention is likely to occur if they do not deal with events efficiently. The ultimate decision for the officer rests upon how much time, effort, or resources should be devoted to any particular case. These decisions are made even more important by the organizational management structure. Officers have greater autonomy in incident disposition than they do in work quantity assigned. In these situations, officers have incentives to focus on more serious crimes and reduce the amount of time spent on minor crimes (Lipsky 1980).

There are two exceptions to these negotiations. First, homicide always results in vigorous police actions, regardless of other situational or organizational factors. Second, events threatening officer safety will always receive vigorous police actions. These events are never considered normal; they always result in the most vigorous law enforcement efforts.

\section{Evaluations of Negotiated Order in Patrol Work}

An extensive literature search reveals only a few studies aimed directly at assessing the key points of Klinger (1997) theory. The first of these studies, Hassell (2005), shed a great deal of light on many of Klinger's key postulates. The study was conducted (using field work, 
interviews, and administrative data) in an undisclosed Midwestern city police department with 760 sworn police officers. Hassell found only limited support for a number of Klinger's key theoretical components. Numerous key predictions were not supported by the findings. Hassell (2005) concluded that the general causal model demonstrated utility in analyzing police activity. Perhaps most importantly, police patrol practices did demonstrate substantial variation at the district level. As such, the district level was a valid aggregate unit for study. The more specific and nuanced predictions made by the model, however, were unsupported by the findings.

More recently, Sobal (2010a) examined if Klinger's theory of negotiated order could be used to explain whether district crime and deviance levels shape police attitudes toward residents. Sobal's study used data from the Project on Policing Neighborhoods (POPN), which collected data from two cities, Indianapolis, IN, and St Petersburg, FL. These data included social observations, census data, police crime records, interviews with officers. Controlling for individual and organizational factors, Sobal found that district crime rates did influence levels of police cynicism. Officers assigned to higher-crime districts had higher levels of cynicism. Sobal also found that officers with more experience had lower levels of cynicism. Sobal's findings provide support for Klinger's argument that district crime levels influence levels of police cynicism.

In another study, Sobal (2010b) used the POPN to conduct a partial test of Klinger's theory, specifically focusing on officer cynicism and workload and how they influence the vigor of police response. The results of the study found little influence of cynicism and district workload on the crime/vigor relationship as proposed by Klinger. These results suggest that other factors may be influencing the crime/vigor relationship.

While Sobal's studies represent an important step in the testing of Klinger's work, there is a need for continued study of Klinger's theory. The present study provides an additional test of Klinger's theory from a different perspective than that of Sobal, exploring whether it is possible to measure the relationship between officer staffing and the quantity of "work" produced. Furthermore, the present study also provides a test of Sobal's work and may help clarify his findings, and it also adds a temporal component to the analysis that other studies have not included.

\section{The Effects of Neighborhoods on Policing}

Broadening the scope of relevant research produces numerous studies that have considered the relationship between community sociostructural factors and the police. With few exceptions, researchers have found that neighborhood characteristics have a substantial impact on police activity. ${ }^{2}$ The effects of neighborhoods and underlying sociodemographic characteristics cannot be overestimated (Bayley and Mendelsohn 1969). This finding has important implications for Klinger's theory. The true nature of police vigor will be most manifest in situations that have the most situational ambiguity. Therefore, an analysis of patrol officer vigor is most likely to result in variation in regard to acts that are considered less serious. We are most likely to see variations in the application of vigor for events that are of a less serious nature, and this variation will be based on the factors laid out in Klinger's theory.

\footnotetext{
${ }^{2}$ One of the few exceptions to this finding was the research conducted by Slovak (1986) analyzing police activity along three dimensions (police-initiated activity, percentage of cases formalized, and police response time) at the neighborhood level in three cities. Although neighborhoods did vary significantly on all three measures, these variations were often substantively small.
} 
Reiss and Bordura (1967) argue that informal practices in police departments allow officers to vary their use of formal authority depending on the position of the social group involved-and specifically that police may accept higher levels of crimes among disadvantaged minority communities. If this premise is true, the relationship may manifest itself in a manner consistent with predictions under the ecological theory of policing.

With rare exceptions, such as Slovak (1986), the literature has consistently shown that community factors affect where and how police services are delivered (Terrill and Reisig 2003). For example, Terrill and Reisig sought to examine the effect of neighborhood on police use of force. Using data from the POPN, social observations, census data, police crime records, and interviews with officers, Terrill and Reisig (2003) found support for the notion that neighborhood influences police use of force, with police being more likely to use higher levels of force in neighborhoods with greater levels of disadvantage. Underlying the discussion of how police services are delivered is the idea that police operate with a great deal of discretion.

\section{Data}

These analyses use data provided by the Philadelphia Police Department (PPD). The fourth largest department in the country, the PPD employs over 6300 uniformed police officers and has an annual operations budget of over $\$ 600$ million (Philadelphia Police Department 2016a, b). It has six patrol divisions and 25 districts (Philadelphia Police Department 2008b). For reasons articulated by Klinger, and because of the organizational structure of the PPD, the district is the organizational unit appropriate for this analysis. Twenty-three districts were included in this analysis. Two special-purpose districts, the Philadelphia International Airport and Fairmount Park, are excluded from this analysis because of their special role within the department and their substantially different operational mandates compared with those of other districts. Although not used in the models, socioeconomic characteristic of police districts can be found in Table 1.

The ecological theory proposes a relationship between environmental and organizational variables and general police actions. These actions are on a scale of formal authority ranging from high vigor to leniency. The dependent variable, therefore, must quantify an officer's actions along this continuum. The outcome measure was the number of incidents that were unfounded per district per month. In Philadelphia, events are unfounded only if an officer investigates a call and no offense or incident was completed or attempted. This disposition code is intended for use only when officers take no action on the call. Events

Table 1 District-level descriptives

\begin{tabular}{lcccc}
\hline Characteristic & Min & Max & Mean & SD \\
\hline Population & $25,266.36$ & $124,705.82$ & $65,892.80$ & $30,174.69$ \\
Percent black in police district & 3.0 & 94.0 & 42.7 & 32.9 \\
Percent population hispanic & 1.0 & 55.0 & 8.1 & 12.8 \\
Percent residents with tenure more than 5 years & 36.0 & 69.0 & 60.8 & 8.5 \\
Percent with less than high school education & 11.0 & 52.0 & 30.6 & 11.1 \\
Percent of housing units owner occupied & 29.0 & 73.0 & 56.9 & 12.5 \\
Median household income & $\$ 10,879.73$ & $\$ 60,161.31$ & $\$ 30,214.54$ & $\$ 13,420.85$ \\
\hline
\end{tabular}

$\mathrm{N}=23$ 


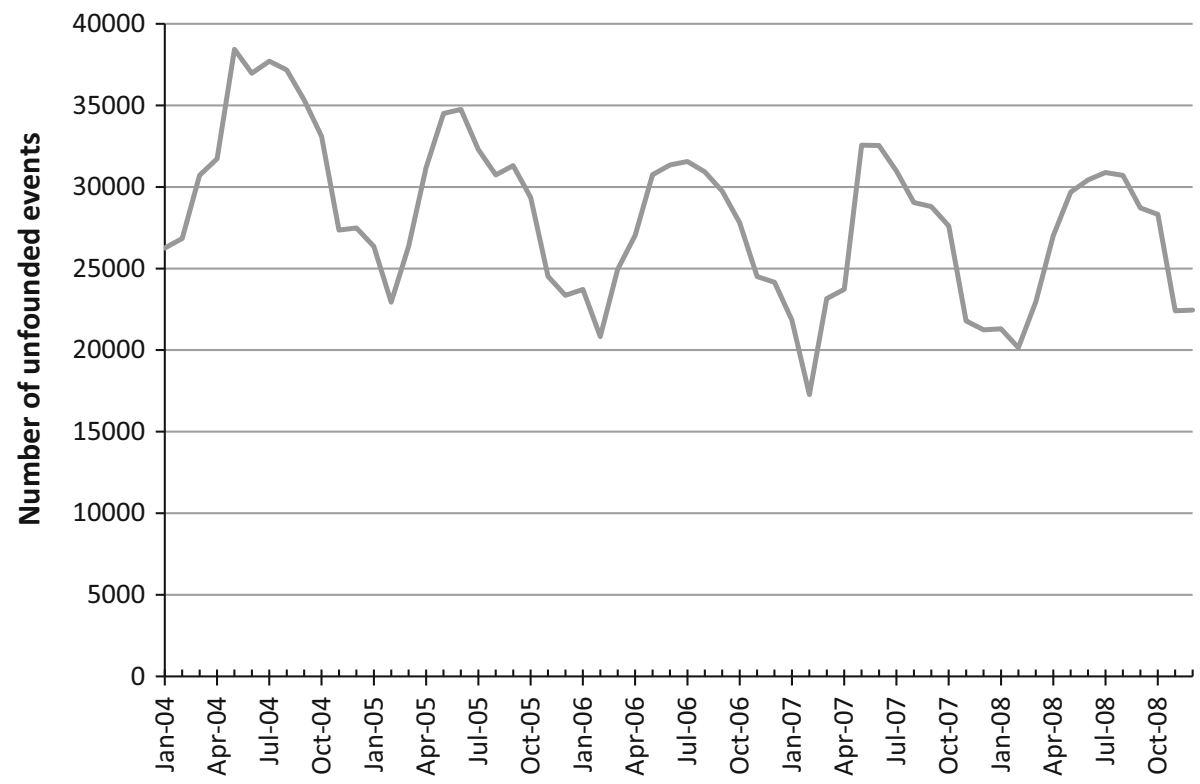

Fig. 1 Citywide temporal trends of unfounded events

that are founded represent more officer vigor than cases that are unfounded. Unfounding an event occurs at one of the earliest stages of processing. The ecological theory predicts systematic variation in the number of unfounded calls: The highest-crime districts should have the highest number of unfounded calls, as officers seek to balance their workload by not exercising authority in low-seriousness events. ${ }^{3}$

Figure 1 demonstrates the number of unfounded incidents during the study period.

Unfounded events have been used in previous studies of police activity. For example, Maxfield et al. (1980) used the ratio of founded to unfounded events to investigate police performance. They found three key things. First, there were dramatic differences between what callers reported to dispatchers and what police officers officially reported. Second, and consistent with the theory being tested here, the ratio of founded to unfounded events was dependent upon the district's level of demand for police services. Higher demand for police services in a given district was related to a greater percentage of unfounded events. Finally, the relationship between founded and unfounded events was not dependent upon racial or socioeconomic characteristics of the area where the event occurred.

Black (1970: 734) argued that reported events, unfounded events, and the relationship between them represent "an empirical phenomenon with its own existential integrity." He posited that the study of unfounded events could be used to inform about police understanding of deviance (in contrast to a citizen's understanding of deviance).

\footnotetext{
3 We note that this is correct only insofar as the average seriousness of the calls to which officers are dispatched in each district is taken into account. It could well be that, in some districts with very high levels of crime, officers are dispatched to a very large proportion of serious crimes, which would prevent unfounding a high number of calls. Similarly, it is possible that in low-crime districts officers are dispatched primarily to trivial matters that do not involve an actual crime, which would lead to high levels of unfounding.
} 
Note that we do not argue that unfounded calls are without merit. It is unknown whether events are unfounded because they are truly non-events or because officers are using their discretion to reduce their workload. This variation in the application of the unfounded disposition is critical to the current study. We use unfounded events to better understand how police officers shed workload in the face of varying levels of serious crimes and officer resources.

\section{Independent Variables}

District workload is a critical component to the ecological theory of policing. Except in situations of homicide and threats to officer safety, vigor toward less-serious events is reduced when workload is high and resources are scarce. These crime types, therefore, make an excellent measure of officer workload. However, because the count value of homicides becomes unstable when broken down by months and by districts, this measure could not be adopted for these models. Instead these models employed serious crimes ${ }^{4}$ as a measure of officer workload. The number of officer assaults, as an additional proxy for officer workload, was also included as an independent variable.

Officer staffing levels are critical to the relationship between vigor and crime for two reasons. First, the ecological theory argues that the relationship between crime and officer staffing levels, not the absolute values of either, determines how vigorously officers respond to an incident. Second, because police strength has been linked theoretically and empirically to police effectiveness (Crank 1990; Klick and Tararrok 2005; Levitt 1997, 2002; McCrary 2002), higher levels of police presence may act as a deterrent to crime. Officer staffing was measured with two variables: (1) the number of patrol officer-hours worked within each district and (2) the number of officer overtime hours worked within each district. These measures were constructed from deidentified officer staffing records obtained directly from the PPD. The records contained the work status (for example, if the officer was working, on vacation, or out sick) of every officer within the department. Data were obtained from the second Tuesday of every month during the study period. This day was selected because it represented an "average" day for the department that was free from overlapping shift schedules. The officer staffing on the second Tuesday of the month was used to represent the officer staffing level of each district for that specific month.

From this dataset it was possible to identify officers working on patrol and the district to which they were assigned. The first step was to select only cases that were assigned to districtspecific units. Officers that were assigned to specific districts were then further parsed so that only officers assigned to patrol were selected. After these cases were selected, the number of hours each officer worked was calculated. These officer-hours were then aggregated by district to produce a district-level, temporally variable, measure of officer staffing.

Although this measure of officer staffing captures the majority of patrol resources, it does not address officers who may be working overtime or during times when they are not normally scheduled. To capture these numbers, we constructed a separate measure of the number of overtime hours officers were working in each district. Overtime hours were

\footnotetext{
4 There was a need to distinguish between serious and less-serious incidents. Less-serious incidents are regarded as providing the officer with more ambiguity about the necessary course of action and therefore greater discretion on how much official authority to exercise. The more-serious versus less-serious distinction was made on the basis of Federal Bureau of Investigation's (FBI) Uniform Crime Reports (UCR) Part One and Part Two offenses. Serious offenses-Part One-include homicide, rape, robbery, aggravated assault, residential and nonresidential burglaries and attempts, theft, vehicle theft (attempts and recoveries), and arson.
} 


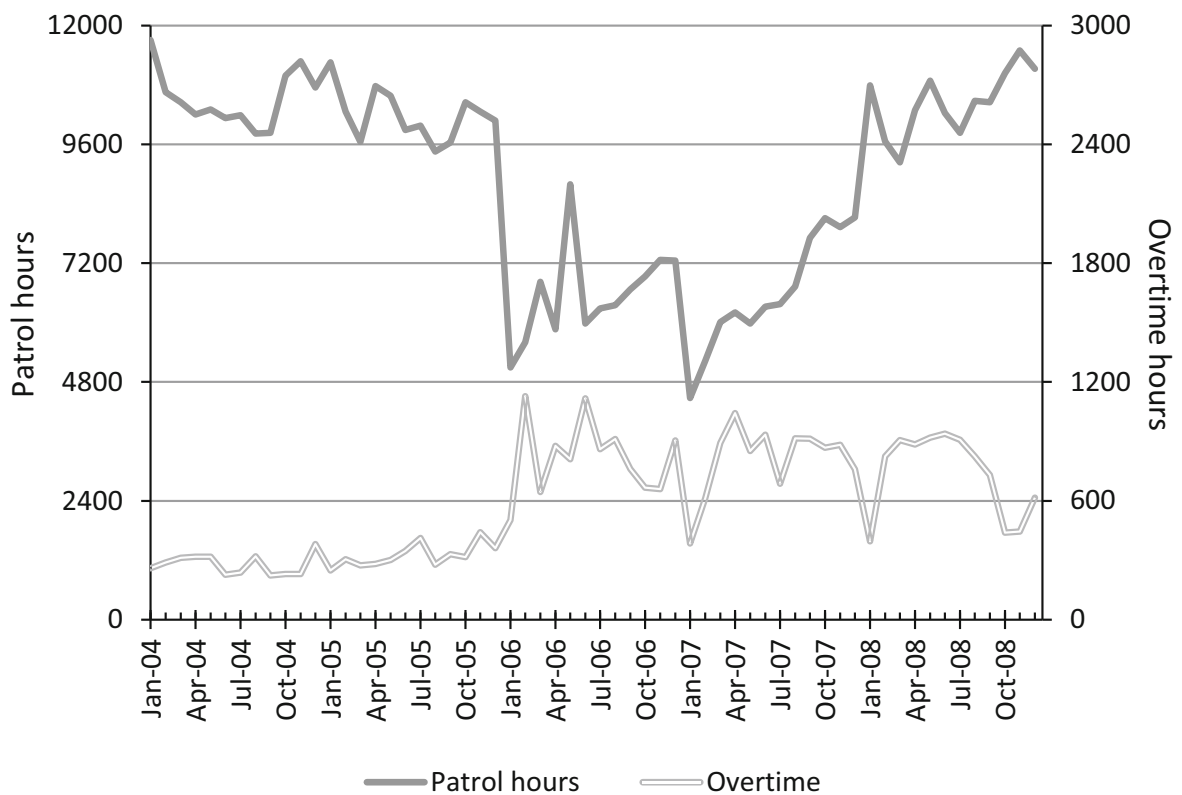

Officer hours calculated on the second Tuesday of every month. Includes officers assigned to patrol within districts.

Fig. 2 Officer-hour and overtime-hour trends

calculated for activities that could be related to patrol but excluded hours earned for appearing in court or other non-patrol-related capacity (e.g., sporting events or parade routes). Figure 2 illustrates citywide trends for officer-hours and overtime hours.

Several limitations to these measures must be considered. First, because the dataset is limited in geographic identifiers, it was not possible to account for special units (such as the narcotics strike force or highway patrol) that are not assigned to a single district. Second, the use of 1 day to represent each month's officer staffing level presents the possibility that things may change substantially from day to day. Ideally, each daily activity measure would be averaged over the entire month. Given the time-consuming nature of requesting data (a rather substantial imposition on the PPD) and the necessary data processing, this was not feasible. Descriptive statistics for monthly time-varying variables can be found in Table 2 .

This analysis required population data for the study period, 2004-2008. Because the U.S. Census is conducted only once every 10 years, we had no readily available sources of demographic data at the spatial and temporal resolution required by this analysis. Instead this study employed demographic estimates created by GeoLytics ${ }^{5}$ (2009). These postcensal estimates are not without their limitations. In general, they are less accurate for smaller geographies and less accurate the farther away in time they are from the original data source (Raymondo 1992). Nevertheless, these data provided the best possible solution to the otherwise intractable problem of conducting longitudinal analyses on variables that are contingent upon the changing sociodemographic fabric of the community.

\footnotetext{
5 Details of GeoLytics' estimation methodology can be found at http://www.geolytics.com/. Changes created by the birth, death, or moving of residential populations are used to create estimated census population data, which are then verified against yearly municipality census counts.
} 
Table 2 Descriptive statistics for monthly varying variables

\begin{tabular}{lcccrccc}
\hline & Mean & Median & SD & \multicolumn{1}{c}{ Variance } & Skewness & Minimum & Maximum \\
\hline Unfounded events & 1219.04 & 1066 & 690.44 & $476,711.60$ & 1.08 & 63 & 4059 \\
Serious incidents & 328.22 & 324 & 133.29 & $17,765.43$ & 0.34 & 71 & 803 \\
Officer assaults & 1.22 & 1 & 133.29 & 2.70 & 2.06 & 0 & 10 \\
Patrol hours & $411: 01$ & $408: 06$ & $20: 53$ & $13,944.52$ & 0.22 & $155: 45$ & $753: 30$ \\
Overtime hours & $26: 13$ & $23: 00$ & $20: 53$ & 436.22 & 1.11 & $0: 00$ & $166: 39$ \\
\hline
\end{tabular}

$\mathrm{N}=1380$

Crime is an inherently spatial process (Griffiths and Chavez 2004; Unwin and Unwin 1998), and any analysis conducted must explicitly control for this spatial patterning or run the risk of false indicators of significance and biased parameter estimates (Anselin 1999; Messner et al. 1999). Calculation of the measure of spatial association was conducted on the monthly count of events in each district. Moran's I values were calculated with a Euclidean-based inverse distance weights matrix. The default neighborhood search threshold was calculated to be 13,947 feet (the minimum distance required to ensure that all police districts had at least one neighbor). Moran's I values ranged from $<0.01$ to 0.27 and were generally, but not always, nonsignificant and varied depending on the month under investigation. A three-nearest-neighbor spatial lag variable created using the spatial data analysis program GeoDa (Anselin 2004) was used to control for any possible spatial effects. The three-nearest-neighbor approach creates a spatial lag value from the crime counts of the three police districts closest to the target district. A unique spatial lag variable was created for each month. To prevent the artificial creation of isolated police districts, we included all 25 districts in this calculation.

\section{Analytical Technique}

A critical choice must be made between using the crime rate or the count of crimes as the dependent variable (Harries 1991). Many analyses use a rate variable as an outcome where the numerator is the phenomenon of interest and the denominator provides an adjustment for the environmental risk or opportunity (Harries 1991). Several limitations to the use of rates as dependent variables have been identified. Most importantly, including a denominator in the dependent variable changes the relationship between the outcome of interest and the independent variables. Because the numerator and the denominator may interact with unmeasured variance in different ways, the use of rates can be problematic (Gibbs and Firebaugh 1990). From a statistical perspective, the use of rates creates problems when dealing with rare events. The precision of the estimated crime rate varies by population size. Predictions of crime rates would be expected to produce larger errors in areas of low population and smaller errors in areas of high population, violating the assumption of homogeneity of error variance (Knoke et al. 2002). Additionally, the error terms will not be normally distributed when the number of events is small. Error terms become increasingly skewed as crime rates approach zero (Osgood 2000). Under these circumstances, count regression models are appropriate (Long and Freese 2006) and were therefore adopted in these analyses. ${ }^{6}$

\footnotetext{
${ }^{6}$ The outcome variable followed an overdispersed Poisson distribution. Therefore all models were specified as Poisson with overdispersion.
} 
Nonlinear, longitudinal, multilevel models were employed to investigate the relationship between changing crime trends and their impact on officer vigor. Multilevel modeling was used because it allows for investigation of temporal trends while respecting the district boundaries as an important organizational unit. The level-1 unit, months included timevarying covariates such as the district-level serious incidents and the availability of police resources (measured through the sum of officer staffing hours). This analysis was conducted on 5 years (2004 through 2008) of monthly $(n=60)$ crime data. The level-2 unit of analysis was police districts $(n=23)$. The outcome measure was the count of unfounded events per month, per district.

All multilevel models were specified so that the predictor variables were group mean centered (subtracting the level-2 district mean value from the level-1 value). The longitudinal models were conducted to investigate the temporally dynamic trends of officer vigor. By group mean centering the independent variables, the models are investigating the change in officer vigor within each district over time, thus allowing for the investigation of changing dynamics within the district.

A priori analysis of power was conducted using Optimal Design for Multi-level and Longitudinal Research (Version 1.77) (Liu et al. 2006). Power in multilevel modeling is sensitive to four factors: (1) the number of level-1 and level-2 units, (2) the effect size, (3) the alpha level, and (4) the intraclass correlation coefficient (ICC) (Raudenbush 1997; Raudenbush and Liu 2000; Spybrook et al. 2008). The number of level-1 units was consistent across all level-2 units $(\mathrm{n}=60)$. Second, consistent with Cohen (1992), effect sizes (Cohen's $d$ ) of $0.20,0.50$, and 0.80 were selected to represent small, medium, and large effects, respectively. An alpha level of 0.05 was adopted. Fourth, following Raudenbush and Liu (2000), ICC values of 0.05, 0.10, and 0.15 were adopted to represent small, medium, and large variances, respectively. Using these assumptions about effect size, alpha levels, and ICC values, we determined power to be acceptable under large and medium effect sizes.

\section{Results}

Local indicators of spatial association (LISA) values indicated high levels of unfounded events clustered (high-high) in North Philadelphia and smaller clusters in the south. Significant low-low clusters could be found in the northwest section of Philadelphia, along with a smaller cluster located near Center City (the central business district of Philadelphia). Figure 3 shows the location of significant unfounded event clusters.

The analysis of variance (Table 3, Model 1) indicated an average of 1067 unfounded events per month, per district, during the study period. Longitudinal multilevel models can be found in Table 3 .

\section{Ongoing Temporal Trends}

The linear time trend variable indicated a significant decline in unfounded events during the study period. The number of unfounded events was decreasing roughly $1.2 \%$ per month across all districts (Model 2). The quadratic variable was positive and significant, indicating an accelerating positive trend in the number of unfounded events during the study period. Although the overall trend may be decreasing (as indicated by the linear trend variable), there was a significant uptick in unfounded events toward the end of the study 


\section{LISA clusters of unfounded events}

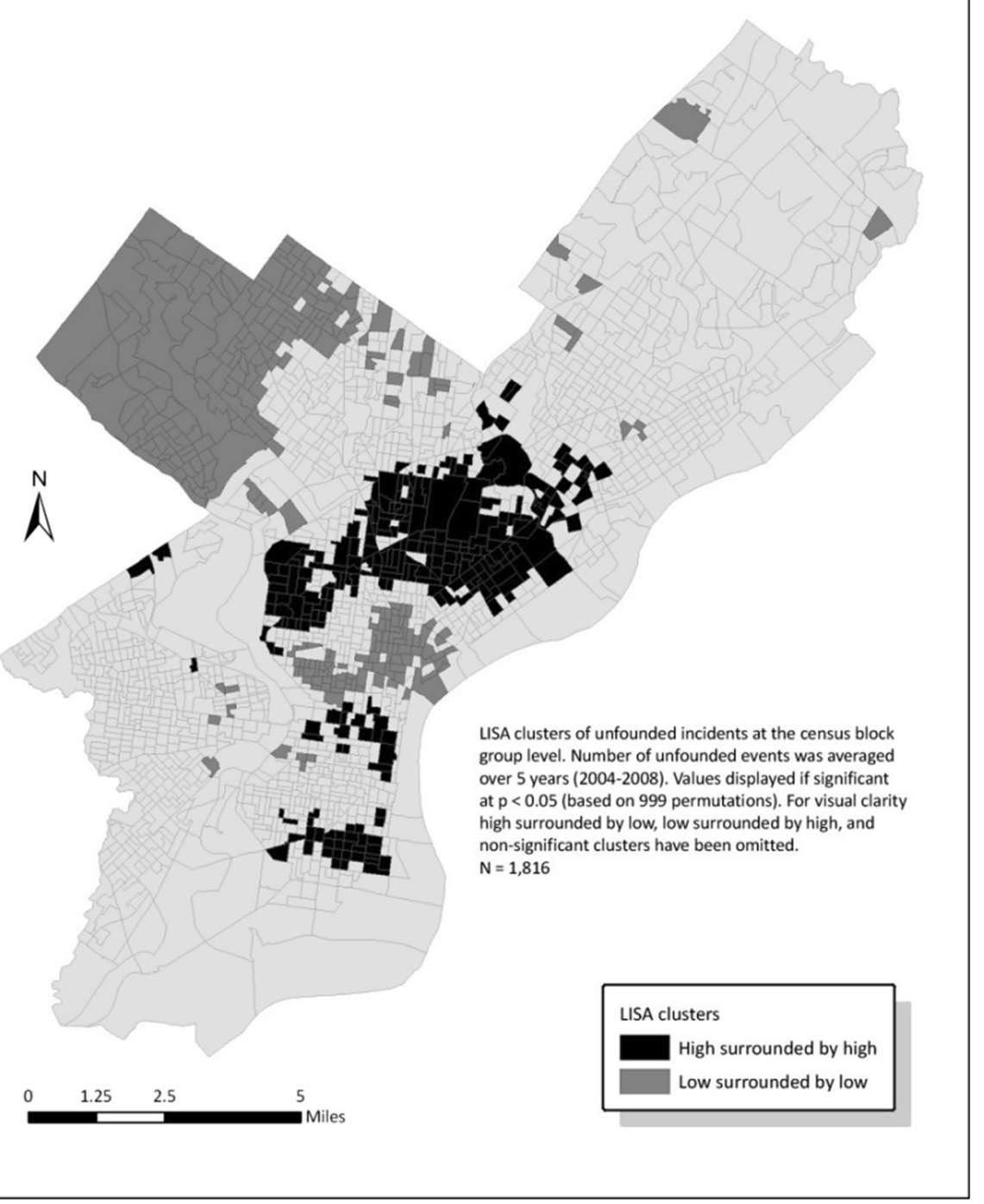

Fig. 3 LISA clusters of unfounded events

period. The temperature variable ${ }^{7}$ was significant and positive, indicating that a 10 -degree change in temperature was related to an $8.5 \%$ increase in the number of unfounded events per month, per district (Model 2). The number of days was also associated with the number

\footnotetext{
${ }^{7}$ Historical weather data were retrieved from the Weather Underground (www.wunderground.com) History and Data Archive. The variable was created by calculating the daily average, monthly average temperature (the average daily temperature averaged over the month).
} 


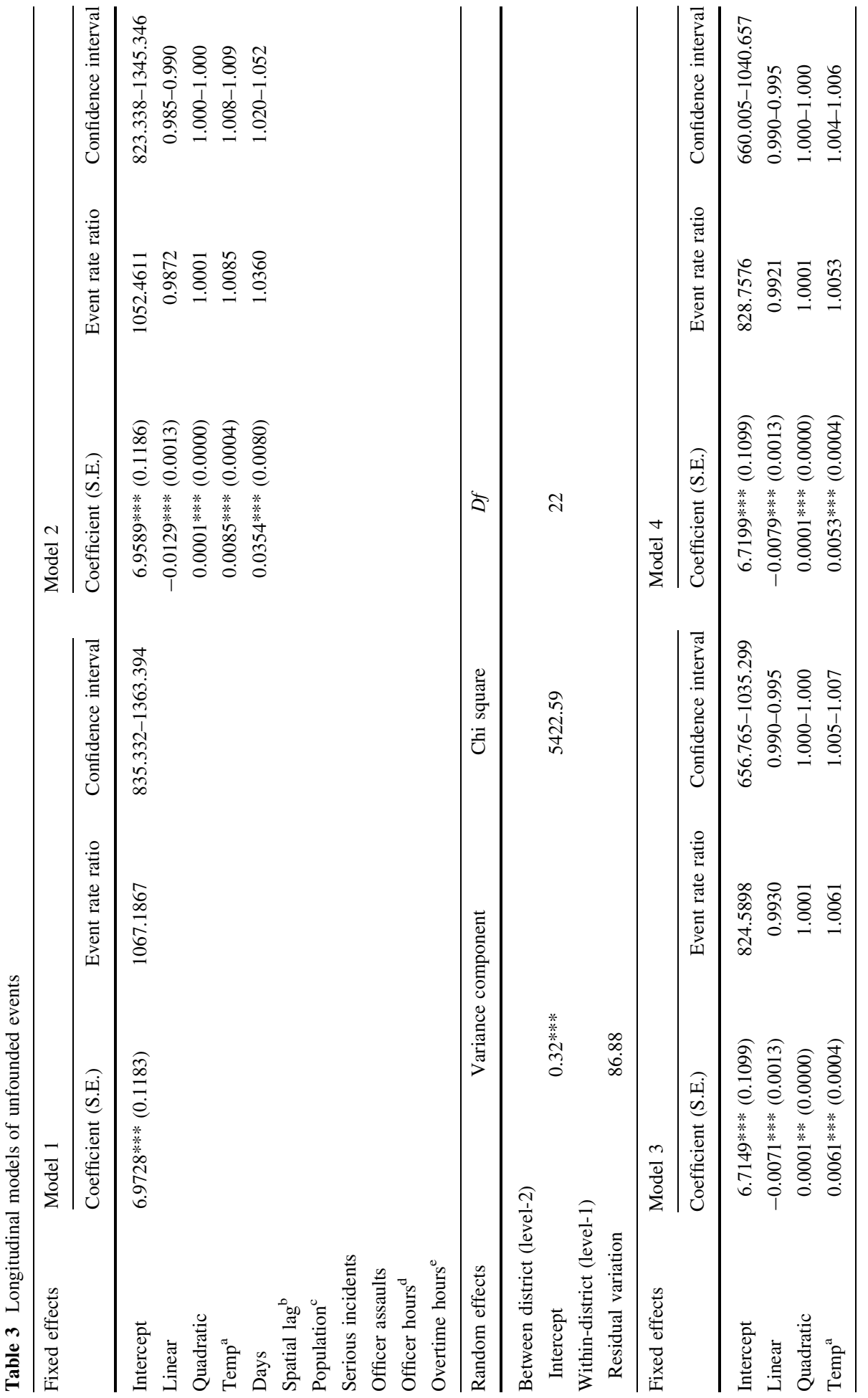




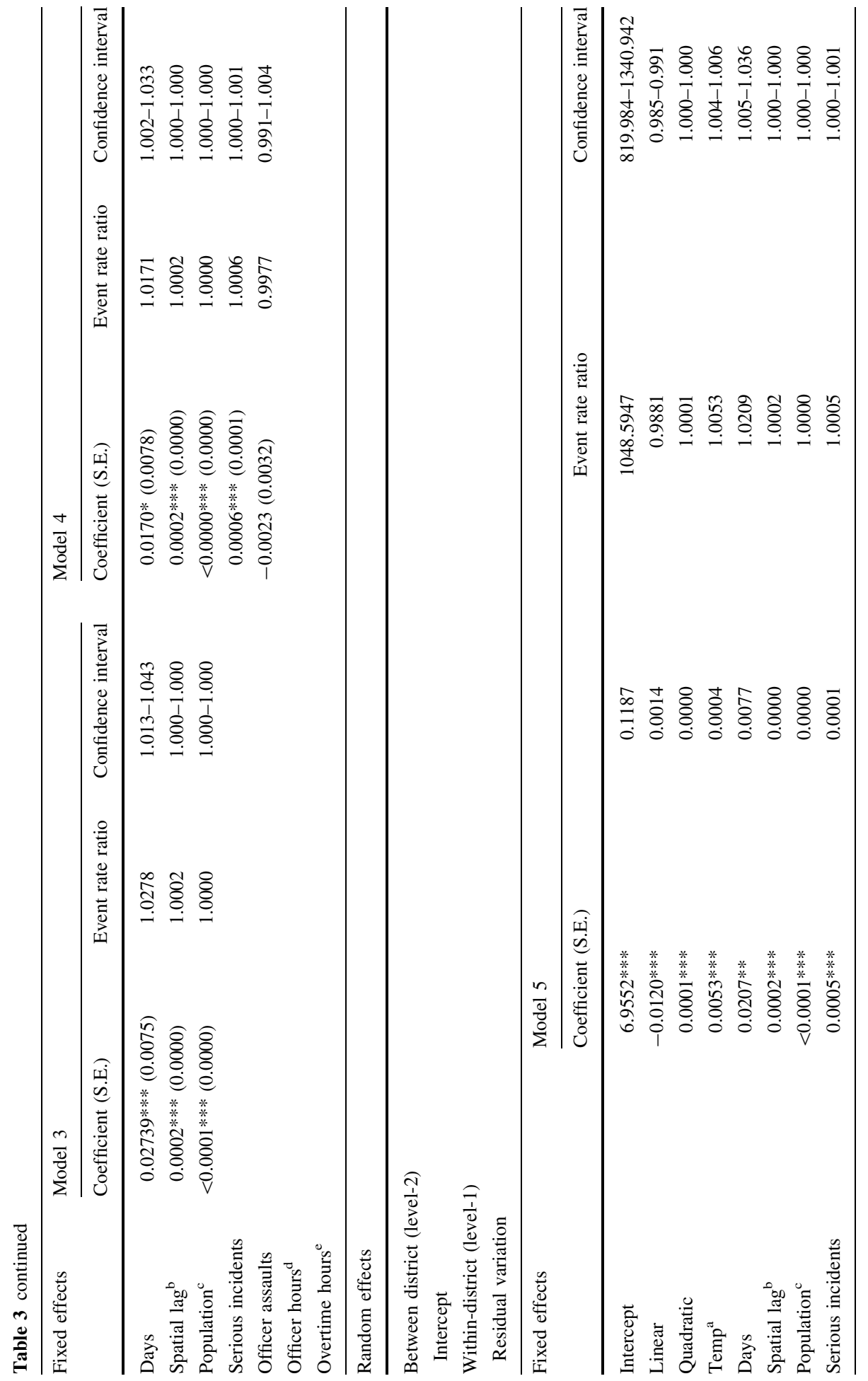




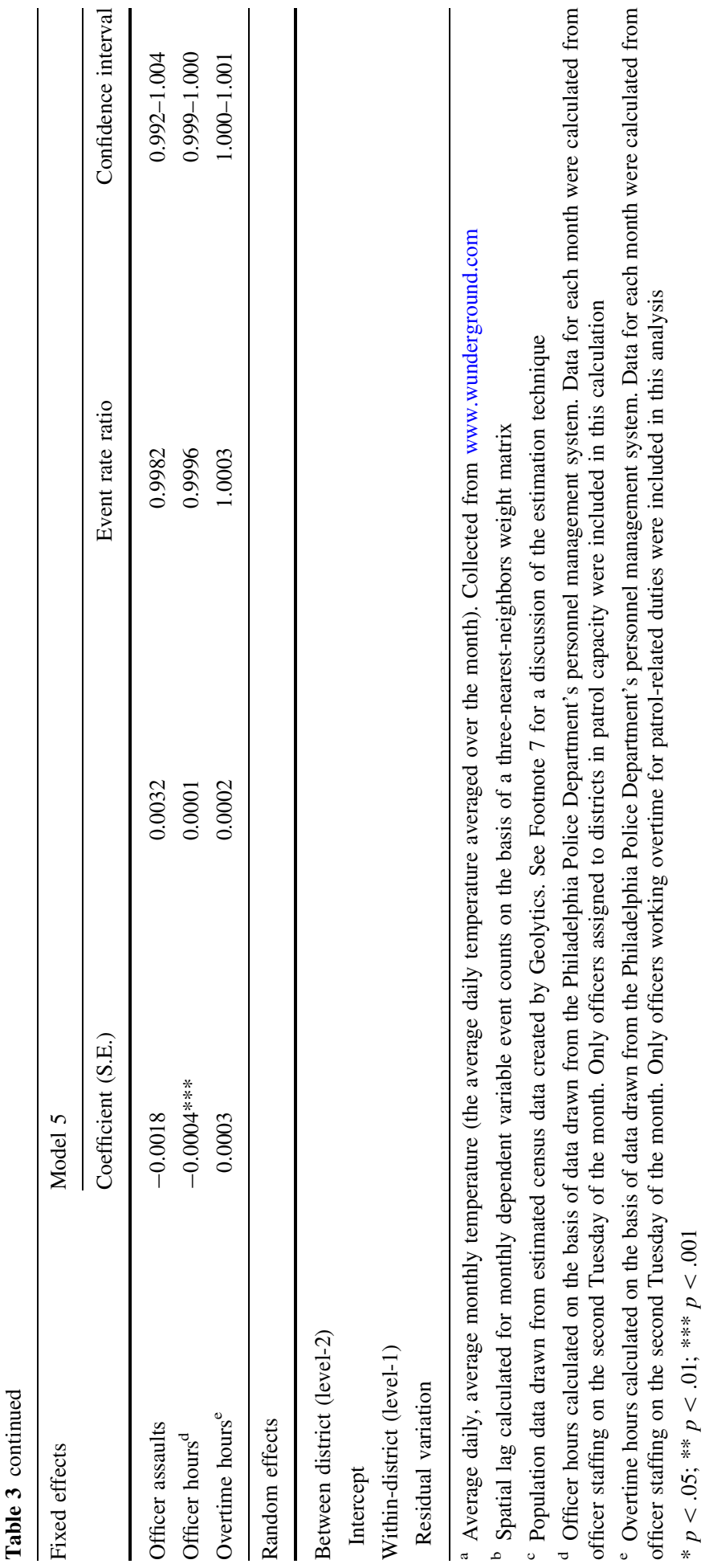


of unfounded events. Adding one additional day per month was associated with a $3.5 \%$ increase in the number of unfounded events per month, per district, net of other temporal trends (Model 2). The direction, general magnitude, and significance of these variables were consistent across model specification (compare Models 2 through 5).

\section{Population and Spatial Effects}

Population and spatial effects were added beginning with Model 3. The spatial lag term was positive and significant, indicating that higher levels of unfounded events in neighboring police districts were significantly associated with higher levels of unfounding in the target district. Population was also positively and significantly related to the number of unfounded events. A 1000-unit increase in the count of residential population was associated with a $4 \%$ increase in the expected count of unfounded events, net of ongoing trends (Model 3). Both population and the spatial lag terms were positive and significant across all model specifications.

\section{Workload}

Serious incidents were positively linked to the number of unfounded events. On average, a 100 -unit increase in the number of serious incidents per month, per district, was associated with a $5.5 \%$ increase in the number of unfounded events per month, per district, net of spatial effects, population, and ongoing temporal trends (Model 5). The number of officer assaults was not significantly related to the number of unfounded events (Models 4 and 5).

\section{Officer Staffing}

Both the number of officer hours assigned to patrol and the number of overtime hours for patrol purposes were entered into Model 5. Consistent with theoretical predictions, a 100-h increase in officers assigned to patrol was associated with a $4.4 \%$ decrease in the number of unfounded events, net of workload, population, spatial effects, and ongoing temporal trending, per month, per district. The number of overtime hours was not significantly related to the count of unfounded events (model 5).

\section{Discussion}

Vigor, as operationalized by the number of unfounded events, was consistently related to workload (operationalized through the number of serious incidents). Higher workload was associated with higher levels of unfounded events, net of other relevant characteristics. Officer staffing was also consistently related to the level of vigor in the direction expected based on theoretical predictions. A greater number of officer hours were associated with fewer unfounded events, suggesting that greater patrol resources reduces the number of unfounded events.

We note that these relationships were statistically significant but relatively small in magnitude. Rather large changes in staffing or workload would be needed to produce small changes in unfounded activity. The fully specified model suggests a 100-unit increase in serious incidents per month was associated with a $5.5 \%$ increase in the number of unfounded events. For the "average district" in the "average month" this would amount to 
a 30\% increase in violent crime. The relationship between staffing and unfounded events was similar. A 100-h increase in patrol staffing was associated with a $4.4 \%$ decrease in unfounded events. For the "average district" in the "average month" this change would amount to a $25 \%$ increase in staffing. Future research should focus on better operationalizing workload and staffing to assess these relationships in higher fidelity.

The relation between overtime hours and officer vigor was nonsignificant. One possible explanation for this finding was that it was not possible to accurately classify exactly why officers were getting overtime. If overtime hours were used to process an arrest made toward the end of an officer's shift, then those hours would not have an impact on the outcomes studied here. A measure of overtime hours that captured only the quantity of officer hours worked on the street in a patrol capacity was not possible with the available data.

The spatial lag was significant across all model specifications. Higher levels of unfounded events in the three nearest neighboring police districts were significantly associated with higher levels of the outcome in the target district. This finding was unexpected for a number of reasons. First, the theory argues that the district is the key ecological unit of analysis. Norms regarding workload develop at the district level, which leads to the development of districts that are largely independent of the influence of other districts. The spatial lag variable would suggest that the districts are not as independent as postulated, and perhaps some spatial process was crossing district boundaries. In Philadelphia at least, districts are subsets of larger parts of the city that tend to be more similar in terms of socioeconomics, crime, and disorder. Incorporating other measures on the ecological characteristics of the district may shed light on this relationship. Second, the analytic choices made regarding the decision to group mean center the spatial lag variable means that the spatial lag variable was measuring the influence of other districts on the target districts' change over time. The impact of the spatial lag can be thought of as the unique effect of nearby districts on the time-varying outcome. This implies that there was a time-varying dynamic that crossed district boundaries at work. Finally, given the size of police districts, a strong spatial effect would not necessarily have been expected. Police districts are large, especially when compared with block groups or census tracts. While it would be reasonable to expect that social or environmental processes would cross smaller geographic boundaries, such boundary crossing would be less expected for very large ecological units such as police districts.

It would appear that internal district dynamics are sensitive not only to crime levels within their own district but also to characteristics of the surrounding districts. This finding may indicate that organizational dynamics do indeed cross district boundaries in a way that is counter to theoretical explanations. Alternatively, the spatial lag variable may be picking up the additional patrol-related activity generated by special operation units such as the narcotics strike force or highway patrol.

These models demonstrated that varying levels of officer workload have an impact on an officer's general willingness to investigate potential criminal activity (in the form of unfounded events). This finding links to broader research investigating the relationship between the number of officers in a police department and the crime level in the jurisdiction (see Levitt 1997, for a summary of this research). Although historically researchers have failed to find an association between police staffing and crime levels (Cameron 1988), recent improvements in data measurement and analytic techniques have generated a resurgence in research suggesting that police can indeed reduce crime (see, for example, Klick and Tararrok 2005; Levitt 2002). 
The current research approaches the issue from a different angle and asks if it is possible to measure the relationship between officer staffing and the quantity of "work" produced. These results suggest that there is a significant relationship between officer staffing and officer vigor. This is useful information for police departments that frequently need to argue for adequate officer staffing levels or for departments looking to evaluate issues revolving around staffing levels. This research suggests that realistic changes to the level of officer staffing can have measurable and significant impacts upon the work output of patrol officers. This finding also suggests important avenues for future research. It would be informative to know whether this relationship exists for other types of police activity. For example, what is the relationship between officer staffing and clearance rates? What is the relationship between officer staffing levels and officer call response time? It may also be worth inquiring how officer staffing levels affect case disposition for situations other than unfounded events.

Finding that patrol officer work output is sensitive to both officer resources and officer workload has larger implications for the criminal justice system as a whole. Taken together as a system, this suggests that patrol officers with greater resources or less workload are likely to engage in a greater level of work. This increased work output has the potential to drive unintended consequences for the rest of the criminal justice system. Goldkamp and Vîlcică (2008: 374) refer to these as "system side effects" and caution that intensive police operations may result in negative consequences for courts and corrections. If this is true, then it may be wise to spend this additional capacity on crime prevention initiatives, such as problem-oriented policing, rather than on more enforcement-focused, zero-tolerancetype programs.

\section{Limitations of the Current Study and Avenues of Future Research}

These findings have demonstrated that the operationalization of key theoretical constructs is a critical decision that must be undertaken with great care. Taken as a whole, these results suggest that concepts of "serious" events need further elaboration and clarification. Use of Uniform Crime Reporting classifications to determine serious or less-serious events was originally adopted to avoid arbitrary, subjective, and potentially unreliable estimates. Future development of the ecological theory of policing may require better methods of classifying the seriousness of an event. This may entail surveying police officers to determine their views on the seriousness of crime events. Such a study would need to account for numerous potential threats to internal validity and ensure that officers from all districts, with various ranks, and with a range of tenures are surveyed.

Operationalizing other key constructs presented additional issues. The use of crime data as a measure of officer workload may be problematic. Although Klinger's theory argues that officers are unlikely to unfound serious incidents, this assumption is by no means definitive. Exploring other methods of quantifying workload remains an important avenue for future research. Measurements of officer response times to calls, the length of time an officer spends at calls, or the number of calls an officer responds to (calls for service) may be alternative indicators of officer workload.

Officer staffing hours were found to be significant and in the direction predicted by theory. Our measure of officer staffing was relatively crude, as we were able to measure only 1 day of staffing per month. We were also unable to measure the presence of special units within the districts. This makes it impossible to tease out the impact these additional officers have on vigor and workload. The effect of these additional officers on models 
should be reduced because they typically do not respond to normal calls for service. As such, their impact on patrol officer workload should be relatively small.

Finally, it must be acknowledged that this evaluation is not a comprehensive test of Klinger's ecological theory. A more comprehensive evaluation of these intervening processes would require an extensive, wide-scale data collection effort. Illuminating those intervening processes - for example, the individual and group understandings of crime and deviance-would be best attempted by field observations and interviews with officers. Combining officer-level information about understandings of the normality of crime, the deservedness of victims, or cynicism with administrative indicators of workload and crime levels would allow for a more complete understanding of the theory. The current study must accept that the intervening processes between district workload and the vigor of police action must remain a black box and cannot be disentangled given the information available. The findings of this study, however, suggest that Klinger's theory has enough validity to justify exploring these intervening measures.

\section{Conclusion}

These findings, in general, support the key propositions first laid out by Klinger more than a decade ago. Klinger's ecological theory of policing, as originally conceived, would be very difficult to test directly. No department is going to keep enough time-sensitive indicators to reliably model the underlying dynamic processes (at both the individual and group levels). This lack of relevant indicators is not an insurmountable problem, but addressing it would require extensive, large-scale data collection using both field observations and interviews with officers. A more difficult problem to resolve is the relatively small number of districts found in each department. Even the largest police department in the country has fewer than 100 districts. This issue, again, is not insurmountable. It is possible, for example, to imagine data collection at numerous police departments, thereby ameliorating issues relating to the small number of districts in each individual police department. Taken together, however, these two points may suggest that evaluating Klinger's ecological theory using quantitative methodologies may be practically implausible, if not necessarily impossible. Although directly testing the totality of Klinger's theory may be beyond reach, the current study suggests several ways of expanding and clarifying Klinger's theory in a direction that makes it a more viable subject for empirical assessment.

Perhaps the critical finding from these findings was that vigor varies as a result of officer workload and resource constraint. Although the magnitude was relatively small, greater workload or lower levels of officer resources lowered the quantity of vigor expended. Other findings suggest that further conceptual development is still required. These findings, taken as a whole, suggest that the ecological theory of policing has strength and utility in explaining patterns of police activity but also that a number of issues could use further conceptual clarity.

Open Access This article is distributed under the terms of the Creative Commons Attribution 4.0 International License (http://creativecommons.org/licenses/by/4.0/), which permits unrestricted use, distribution, and reproduction in any medium, provided you give appropriate credit to the original author(s) and the source, provide a link to the Creative Commons license, and indicate if changes were made. 


\section{References}

Anselin L (1999) Spatial econometrics working paper. Center for Spatially Integrated Social Science, Santa Barbara

Anselin L (2004) GeoDA (Version 0.9.5-i5). University of Illinois

Bayley DH, Mendelsohn H (1969) Minorities and the police: confrontation in America. Free Press, New York

Bittner E (1967) The police on skid-row: a study of peace keeping. Am Sociol Rev 32(5):699-715

Black DJ (1970) Production of crime rates. Am Sociol Rev 35(4):733-748

Brogden M (1982) The police: autonomy and consent. Academic Press Inc, New York

Brown MK (1981) Working the street: police discretion and the dilemmas of reform. Russell Sage Foundation, New York

Cameron S (1998) The economics of crime deterrence: a survey of theory and evidence. Kyklos 41:301-323

City of Philadelphia (2008) Fiscal year 2008 operating budget. City of Philadelphia, Philadelphia

Cohen J (1992) A power primer. Quant Methods Psychol 112(1):155-159

Crank JP (1990) The influence of environmental and organizational factors on police style in urban and rural environments. J Res Crime Delinq 27(2):166-189

De Lint W (2000) Autonomy, regulation, and the police beat. Social Legal Studies 9(1):55-83

Durkheim E (1938) The rules of sociological method (S. A. Solvang, Trans), 8th edn. Glencoe, New York Ericson RV (1982) Reproducing order: a study of police patrol work. University of Toronto Press, Toronto Faris REL (1948) Social disorganization. Ronald Press, New York

Geerken MR, Gove WR (1975) Deterrence: some theoretical considerations. Law Soc Rev 9(3):497-513

Geerken MR, Gove WR (1977) Deterrence, overload, and incapacitation: an empirical evaluation. Soc Forces 56(2):424-447

GeoLytics (2009) Annual estimates professional 2001-2008. GeoLytics, East Brunswick

Gibbs JP, Firebaugh G (1990) The artifact issue in deterrence research. Criminology 28(2):347-367

Goldkamp JS, Vîlcică ER (2008) Targeted enforcement and adverse system side-effects: the generation of fugitives in Philadelphia. Criminology 46(2):371-409

Griffiths E, Chavez JM (2004) Communities, street guns and homicide trajectories in Chicago, 1980-1995: merging methods for examining homicide trends across space and time. Criminology 42(4):941-978

Harries KD (1991) Alternative denominators in conventional crime rates. In: Brantingham PJ, Brantingham PL (eds) Environmental criminology. Waveland Press, Prospect Heights

Hassell KD (2005) A cross-precinct analysis of police patrol practices and the negotiation of order among patrol. Ph.D., University of Nebraska at Omaha, Omaha

Herbert S (1997) Policing space: territoriality and the Los Angeles police department. University of Minnesota Press, Minneapolis

Klick J, Tararrok A (2005) Using terror alert levels to estimate the effect of police on crime. J Law Econ XLVIII:267-279

Klinger DA (1997) Negotiating order in patrol work: an ecological theory of police response to deviance. Criminology 35(2):277-306

Knoke D, Bohrnstedt GW, Mee AP (2002) Statistics for social data analysis, 4th edn. Wadsworth/Thomson Learning, Belmont

Lauritsen JL, Sampson RJ, Laub JH (1991) The link between offending and victimization among adolescents. Criminology 29(2):265-292

Levitt SD (1997) Using electoral cycles in police hiring to estimate the effects of police on crime. Am Econ Rev 87(3):270-290

Levitt SD (2002) Using electoral cycles in police hiring to estimate the effects of police on crime: reply. Am Econ Rev 92(4):1244-1250

Lipsky M (1980) Street-level bureaucracy: dilemmas of the individual in public service. Russell Sage Foundation, New York

Liu X, Spybrook J, Congdon R, Martinez A, Raudenbush SW (2006) Optimal design for multi-level and longitudinal research (Version 1.77). University of Michigan, Ann Arbor

Long JS, Freese J (2006) Regression models for categorical dependent variables using Stata, 2nd edn. Stata Press Publication, College Station

Lundman RJ (1979) Organizational norms and police discretion: an observational study of police work with traffic law violators. Criminology 17(2):159-171

Marenin O (1985) Police performance and state rule: control and autonomy in the exercise of coercion. Comp Politics 18(1):101-122

Maxfield MG, Lewis DA, Szoc R (1980) Producing official crimes: verified crime reports as measures of police output. Soc Sci Q 61(2):221-236 
McCrary J (2002) Using electoral cycles in police hiring to estimate the effects of police on crime: comment. Am Econ Rev 92(4):1236-1243

Messner SF, Anselin L, Baller RD, Hawkins DF, Deane G, Tolnay SE (1999) The spatial patterning of county homicide rates: an application of exploratory spatial data analysis. J Quant Criminol 15(4):423-449

Moynihan DP (1993) Defining deviancy down. Am Sch Winter 62(1):17-30

Osgood DW (2000) Poisson-based regression analysis of aggregate crime rates. J Quant Criminol 16(1):21-43

Philadelphia Police Department (2016) Organizational overview. Retrieved 30 October 2008, http://www. ppdonline.org

Philadelphia Police Department (2016) Patrol bureau organization chart. Retrieved 30 October, 2008, http:// www.ppdonline.org

Phillips SW, Sobal JJ (2011) Police attitudes about the use of unnecessary force: an ecological examination. J Police Crim Psychol 26:47-57

Phillips SW, Sobal JJ (2012) Police decision making: an examination of conflicting theories. Polic Int J Polic Strateg Manag 35(3):551-565

Raudenbush SW (1997) Statistical analysis and optimal design for cluster randomized trials. Psychol Methods 2(2):173-185

Raudenbush SW, Liu X (2000) Statistical power and optimal design for multisite randomized trials. Psychol Methods 5(2):199-213

Raymondo JC (1992) Population estimation and projection: methods for marketing, demographic, and planning personnel. Greenwood Publishing Group, Santa Barbara

Reiss AJ, Bordura DJ (1967) Environment and organization: a perspective on the police. In: Bordura DJ (ed) The police: six sociological essays. Wiley, New York

Rengert GF, Ratcliffe JH, Chakravorty S (2005) Policing illegal drug markets: mapping the socio-economic environments of drug dealing. Criminal Justice Press, Monsey

Slovak JS (1986) Styles of urban policing: organization, environment, and police styles in selected American cities. New York University Press, New York

Slovak JS (1987) Police organization and police environment: case study of a disjuncture. Sociol Focus 20:77-94

Smith DA (1986) The neighborhood context of police behavior. In: Reiss AJ, Tonry M (eds) Communities and crime. University of Chicago Press, Chicago, pp 313-341

Sobal JJ (2010a) Social ecology and police discretion: the influence of district crime, cynicism, and workload on the vigor or police response. J Crim Justice 38:481-488

Sobal JJ (2010b) The social ecology of police attitudes. Polic Int J Polic Strateg Manag 33(2):253-268

Spybrook J, Raudenbush SW, Liu X, Congdon R, Martinez A (2008) Optimal design for longitudinal and multilevel research: documentation for the 'Optimal Design' software. University of Michigan, Ann Arbor

Stark R (1987) Deviant places. Criminology 25:893-909

Strauss A, Schatzman L, Bucher E, Sabshin M (1963) The hospital and its negotiated order. In: Freidson E (ed) The hospital in modern society. Free Press of Glencoe, New York

Sun IY (2002) Police officers attitudes toward peers, supervisiors, and citizens: a comparison between field training officers and regular officers. Am J Crim Justice 27:69-83

Terrill W, Reisig MD (2003) Neighborhood context and police use of force. J Res Crime Delinq 40(3):291-321

Udy SH (1959) 'Bureaucracy' and 'rationality' in Weber's organization theory: an empirical study. Am Sociol Rev 24(6):791-795

Unwin A, Unwin D (1998) Exploratory spatial data analysis with local statistics. Statistician 47(3):415-421

Weber M (1947) The theory of social and economic organization (Henderson AM, Parsons T, Trans). Oxford University Press, New York

Weisburd D, Wyckoff LA, Ready J, Eck JE, Hinkle JC, Gajewski F (2006) Does crime just move around the corner? A controlled study of spatial displacement and diffusion of crime control benefits. Criminology 44(3):549-591

White SO (1972) A perspective on police professionalization. Law Soc Rev 7(1):61-86 